\title{
When civil protection meets urban planning: conceptualising a resilient city development process
}

\author{
L. Melkunaite \& F. Guay \\ Danish Institute of Fire and Security Technology, Denmark
}

\begin{abstract}
It is the first time in history that more people are living in cities than in rural areas. As urban space has become the central aspect of modern societies creating new types of vulnerabilities, resilience has emerged as a key priority for urban planners as well as civil protection officers aiming to build smart and more disaster resilient cities. There is a large set of urban planning practices, such as hazard mapping and building permits, aiming at increasing urban disaster resilience. However, there is still a lack of endeavour to research how these urban planning processes are being incorporated into national civil protection systems. Therefore, this paper aims to bridge the gap and analyses the relationship between urban planning and civil protection in conceptualizing resilient space planning processes. In this paper, using a case study approach, we examine if and how, the Danish Emergency Management Agency (DEMA) integrates urban planning and civil protection in Denmark in order to build more resilient cities. To do this, we draw upon the knowledge of those working within the urban planning and civil protection systems to identify the opportunities and obstacles for the existence of their cooperation. Copenhagen, ranked the world's most climate resilient city, was selected for the urban planning case analysis, as well as Vejle, being part of the "100 Resilient Cities" network. The results indicate that although both DEMA and urban planners aim to build disaster resilient cities and wish to contribute to creating a more resilient society, the dialogue between the two bodies is almost non-existent with regards to resilient urban space planning processes.
\end{abstract}

Keywords: resilience, urban resilience, civil protection, urban planning. 


\section{Introduction}

Nowadays, the world's population is urbanizing more rapidly than at any time in human history. Growing populations and increased density make cities more vulnerable to disruptions, crises, and disasters in many ways. For example, fast expansion of the cities has resulted in building infrastructures in hazard prone areas, developing urban areas that have highly negative impact on ecosystems, or burdening social and economic systems. Due to a highly interconnected environment, modern cities have become particularly prone to domino events and cascading effects. According to the World Bank's estimate, in the period between 1980 and 2012, nearly $\$ 4$ trillion has gone into relief and recovery efforts worldwide for natural disasters alone [1]. There is increasing evidence of how investment in resilience can reduce the amount of money spent on recovery and relief through avoided losses. Therefore, there is no question that building resilience in modern cities should be a priority on both national and international political agendas.

In 2011, Copenhagen was declared the world's most climate resilient city [2]. Nevertheless, recently the city has been facing the harsh consequences of cloud burst. In early July 2011, a heavy thunderstorm flooded streets and key roads of Copenhagen in less than three hours, causing a damage of $\$ 1,04$ billion [3]. In September 2014, once again large parts of the city were flooded by heavy rain causing chaos and the shut down of train services [4]. Vejle is yet another Danish city that attempts to include the concept and practice of resilience into its development processes. Vejle is one of the 10 most vulnerable areas in Denmark, facing a high risk of flooding. Scientists predict that by 2100 , the city will be underwater. Vejle is listed among 100 cities participating in the Rockefeller Foundation programme aimed at increasing city resilience around the world [5].

Built on the assumption that in order to build urban resilience there is a need for a holistic approach and involvement of different actors, this paper aims to explore the cooperation between civil protection and urban planning systems. We hope to encourage a much needed discussion and dialogue between urban planners and civil protection representatives on the issue of urban resilience. The paper is divided into six sections, discussing the methodology, the concept of resilience, the concept of urban resilience, actors involved in the process of building urban resilience, research results and our conclusions.

\section{Methodology}

As the current research aims to explore an area that is highly under-theorised, we chose the method of case study analysis as it focuses on a small number of cases that are expected to prove insight into a causal relationship across a larger population of cases [6]. For the purpose of the study, we chose two cities in Denmark, namely Copenhagen entitled as the world's most climate resilient city, and Vejle, a city participating in the Rockefeller Foundation programme "100 Resilient Cities", for further analysis. 
As not all the data can be found in the official state documents and secondary literature, we used semi-structured interviews to retrieve invaluable information from urban planners and designers as well as different actors working within civil protection and emergency management system in Denmark. We used the method of semi-structured interviews having a set of questions that needed to be covered and allowing interviewees a great leeway in how to reply to them [7]. We formed three questionnaires for each of the target group: civil protection agencies, urban planners, and researchers. We conducted five interviews in total. In the Copenhagen region we had phone interview with a representative of the urban renewal office in the climate resilient neighbourhood (Områdefornyelse), a representative of the SLA urban planners company, and a representative from the Danish Emergency management agency. In the Vejle region, we had phone interview with a representative from the municipality, within the project development department. In order to respect the confidentiality of the participants to our interviews, we will not mention their names.

While doing an extensive literature research, the problem of the scarcity of available literature on the topic of resilience in urban planning occurred. In order to solve the problem, we arranged an additional Skype interview with Dr. Alan March, Associate Professor in Urban Planning at the University of Melbourne. The interview helped to fill in the theoretical gaps found in the existing literature as well as provided information of existing urban resilience practices in Australia.

\section{Unravelling urban resilience}

The word resilience is derived from the Latin resilire, resilio, meaning to spring or bounce back. These terms are found in the writings of Seneca the Elder, Pliny the Elder, Ovid, Cicero and Livy [8]. In its modern application, the concept has pierced different disciplines, passing between diverse fields such as engineering, ecology, psychology, disaster studies, organisational management, among many, and this way gathering different and at times contradictory approaches.

It could be argued that there are two major directions in the way how a resilient system should respond to a shock emerged, namely engineering and ecological resilience. When applied in mechanics, engineering, mathematics, and similar disciplines, resilience is focused on system's behaviour near a stable equilibrium and the rate at which a system returns to steady state following some disturbance [9]. Resilience is perceived as an outcome rather than a process, stressing the capacity of a system to cope with unexpected shocks by learning to bounce back or come back to its pre-disturbance state [10]. However, the concept of engineering resilience is more applicable for objects that are capable of returning or regaining their original shape after blending, compression or other deformation [11].

In one of the most influential papers in the discipline Resilience and stability of ecological systems, Holling proved that single equilibrium oriented resilience cannot be applied to ecological systems where the existence of more than one equilibrium is possible [12]. Ecological resilience is the ability of a system to " $[\ldots]$ absorb changes and disturbance and still maintain the same relationships between 
populations or state variables" [12]. The concept of ecological resilience further advanced due to its application in the context of complex adaptive systems (CASs) and social-ecological systems (SESs) [13]. From this perspective, resilience is an adaptive process characterised by systemic re-organisation, renewal, flexibility and development, and where single equilibrium approach is neither anticipated nor desired [14]. Instead of approaching resilience as the system's ability to bounce back after a disturbance, it is perceived as a process of bouncing forward [15].

Over the last decade, the concept of resilience became one of the core concepts in the hazard research. It was fully established in the international political arena in 2005 with the adoption of the Hyogo Framework for Action (HFA) [16]. In the context of disasters, resilience is understood as the capacity of a system, community, or society potentially exposed to hazards to resist, absorb, accommodate and recover from disasters timely and efficiently. This is determined by the degree to which the social system is capable of organizing itself to increase its capacity for learning from past disasters for better future protection and to improve risk reduction measures [17]. Despite the fact that resilience research is abundant, there is still no well-established and unambiguous way how to transfer and actively apply resilience theory in the context of a city in order to increase its threshold towards disasters.

In the urban context, resilience approach is targeted towards making cities more able to respond to shocks and improve the overall delivery of basic functions and services on a daily basis as well as in times of a crisis. A resilient city is able to survive a traumatic shock to its physical infrastructure, its economy, and its social fabric [18]. A resilient city bends but does not break; it is able to absorb impacts without shattering [18]. However, application of resilience in the urban context is a rather difficult task mainly due to the aforementioned discussion on the complexity of the concept of resilience itself. Moreover, urban space is also a highly complex entity referred to as a system of systems having a "[...] rich spatial and temporal heterogeneity - a complex mosaic of biological and physical patches in a matrix of infrastructure, human organisations, and social institutions" [19]. So how does one untangle this complexity of the two phenomena?

Urban resilience is not a new concept within disaster research. Meerow et al. [20] identified 25 definitions of urban resilience in the up-to-date literature, which shows how contested and ambiguous the concept itself is. Drawing from diverse research domains, the concept of urban resilience was traditionally used to denote persistence of a city and therefore was positioned within a single equilibrium resilience perspective [21]. For example, Godschalk [22] suggests that resilient city is "[...] capable of withstanding severe shock without [suffering] either immediate chaos or permanent harm". Yet, in recent years different authors began to emphasize the adaptive component of the concept arguing for a dynamic concept of urban resilience and the ability of a city to adapt to constantly changing environment [21]. In this case urban resilience can be defined as "[...] the ability of an urban system-and all its constituent socio-ecological and socio-technical networks across temporal and special scales-to maintain or rapidly return to desired functions in the face of a disturbance, to adapt to change, and to quickly transform systems that limit current or future adaptive capacity" [20]. 
Resilience approach suggests that urban environments should function and be adopted according to certain key characteristics. Firstly, urban spaces should be built on the principle of diversity in the number of businesses, institutions and sources of energy, food and means of making a living [23]. Secondly, resilient places require a certain degree of modularity or the capacity to reorganise after the onset of a shock in a way that they can meet and supply their core needs without dependence of external sources [24]. Thirdly, resilient places should be characterised by an emphasis on small-scale, localised activities that are embedded in the capacities of the local environment, and cognisant of and adapted to its limits. Finally, at the centre of resilient spaces are resilient communities and families [23].

Asian Cities Climate Change Resilience Network (ACCCRN) argue that resilient cities are able to withstand a variety of challenges because of the redundancy, flexibility, capacity to reorganize, and capacity to learn being integrated into the urban systems [25]. Redundancy: Several urban systems provide similar functions and provide substitutable services when another system is disrupted. Flexibility: Urban systems are able to absorb shocks in ways that avoid catastrophic failure of a system. In case a component or institutions fails, there is minimal impact on other systems. Capacity to Reorganise: Urban systems have the ability to adapt, change and evolve in response to changing circumstances. Capacity to Learn: The ability of urban systems to internalize past experience, respond to it, and avoid repeating mistakes ensures that future decisions are made with appropriate caution and forethought.

Acknowledging the complex nature of an urban space it is thus argued that different components within a city require different resilience approaches. Bouncing back and persistence might be desirable qualities for such urban components as electricity poles; while it is desirable for communities living within a city to positively adapt to urban disasters. Thus one needs to take into account the insights and approaches from engineers, ecologists, economists and psychologists in order to be able to create more disaster resilient cities. Building resilient city requires a holistic, flexible, and multi-sectoral approach to urban development.

\section{Designing resilient city: the actors involved}

It is now widely recognised that different actors should work together to realise holistic urban development processes in order to deliver resilience and sustainability. Integrated urban and territorial planning, risk management, and governance, will have to be coupled with resource and energy efficiency, sustainable production and consumption as well as inclusive economic growth [26]. UNISDR recognized city planners and local governments as the key actors for reducing the risks posed by natural hazards and building resilient urban societies [27]. It should be noted that it is beyond the scope of the current paper to discuss all the actors involved in the process of conceptualising resilient city development process, therefore, we will concentrate on the involvement and collaboration between civil protection agencies and urban planners. 
Civil protection systems can be generally perceived as institutions involved in protection of citizens, property and environment against hazards of any kind [28]. Emergency management organisations fall under the national system of civil protection. In the wake of the resilience hype, there is a need for the adoption of a resilience approach to civil protection to be placed as the top priority at the national and international level of disaster risk management policies. Civil protection organisations were one of the primary governmental actors entitled the role of helping in the process of building community resilience, as well as preparing national strategies for resilience and disaster risk management, including resilience of cities as a constituent part of every country. In order to achieve an overall disaster resilience of a system, one needs coordinated actions where resilience of separate parts of the system comprises and complies with the resilience of the system itself. In the case of Denmark though, responsibility for building a national resilience strategy is not that clear. The Danish Emergency Management Agency (DEMA) is the central civil protection body organized under the Ministry of Defence, and has the purpose to ensure a robust society by developing and strengthening preparedness, in order to prevent and respond to major accidents and disasters. They operate under the Danish Emergency Management Act, which explains in details, who has the responsibility for what, starting from the ministry level down to the municipal level. However, the municipal level is also responsible for emergency management in their area. The Ministry of Defence may lay some rules and preventive measures, and the municipal level can decide to add measures depending on their regional situation. Thus the responsibility for a "resilience strategy" is not clearly attributed to one entity. We will exemplify this further on in our paper.

Urban planning is a relatively young and complex discipline with a series of objectives that need to be achieved [18]. It concentrates on elements such as the use of land, the design of the urban environment, the protection and use of environment, the planning of infrastructure systems such as transportation and communication, etc. In a personal interview, Alan March explained that "urban planning can be perceived as a modifying human activity in physical form over time, thinking how an individual decision will impact the future. It is about integrating decision now with an elective risk outcome in the future". The resilience approach in urban planning assumes that the future cannot be predicted and will include unexpected shocks, and that urban systems must be designed and oriented in ways that serve sudden and unanticipated changes. In a personal interview, Alan March defined urban resilience as a "connection between the spatialisation of risk management and improvement of risk profiles over time as a mechanism for integrating various activities and social, economic and built form outcomes. It is the integration of spatial and physical outcomes that we seek with the social ones and the hazard. Thus resilience in urban planning is all about the integrating force." However, Alan March argued that from the urban planner's point of view, the concept of resilience itself has some challenges, especially the notion of bouncing back which implies the necessity of a shock or disaster to happen in order for resilience to occur. According to Alan March, instead of waiting for a disturbance and testing city's resilience "we need to model different 
scenarios, learn from other instances, transfer learning from other places and think about positive adaptation without even having an event to occur."

\section{Results}

The results of our interviews confirmed our initial assumption that there is no cooperation between the Danish national civil protection agency DEMA and urban planners in conceptualising resilient city development processes. Although all interviewees agreed that there is a need for a holistic approach to urban resilience, in Denmark, national civil protection and urban planning systems operate on different systemic dimensions without any close interaction. Though we could observe that on the municipal level, the involvement of civil protection agencies is present and much needed. Their level of involvement will though depend on the projects and the municipalities.

In Copenhagen, urban planning processes are initiated at the municipality level. However, this municipality does not have any clear strategy for building resilience. The local urban renewal office (Områdefornyelse) is an entity responsible for initiating resilience related projects and applying to the responsible ministry for funding. This office is a decentralized entity of the municipality of Copenhagen, which has been created for a period of only five years, which will expire in mid-2016. Nevertheless, the office does not coordinate their project ideas with the Danish National Emergency Management Agency (DEMA) in any way. Thus, there is no dialogue between the two institutions.

In the past five years, the municipality has focused on climate change adaptation solutions. In the climate resilient neighborhood in Østerbro, this is the first area in Copenhagen to have a program that aims at having a greener neighbourhood, as well as increasing its capacity to withstand the heavy rains. In this case, the urban area office is considered to be the client. Once they received the funding from the ministry of immigration, integration and housing, as well as from the Greater Copenhagen Utility, they opened the projects for urban planners and designers to come up with their proposals on how to renew and adapt the Østerbro district in order to make it resilient to certain challenges and comply with the Climate Neighbourhoods guidelines. For example, in the project of the refurbishment of Skt. Kjelds Plads, storm water was an important challenge. However, applying urban resilience approach, instead of trying to isolate water from the district, the focus was on trying to adapt the physical infrastructures of the city so that water would benefit and not harm the population living in the area. Properties around the square where also involved in the process, by selecting one representative each for the board of administration. All proposed solutions were discussed before selecting a winner which in this case were a team involving SLA urban planners.

We then interviewed SLA urban planners, who did win the aforementioned project in Skt. Kjelds Plads, asking them about their cooperation with other actors and especially with civil protection agencies. There was no consulting with DEMA regarding the project. However, some of the local level civil protection agencies were involved in the process at a certain degree. While developing the project, 
urban planners worked in collaboration with the Copenhagen fire brigade and the Copenhagen police. The fire brigade is responsible for assuring that the project complies with the existing fire security regulations in Denmark. For example, they have to make sure that the fire and rescue vehicles can successfully manoeuvre in the area and reach their destination, and that the citizens can safely move in a certain district in the case of fire. The police are mostly responsible to assure that the regulations concerning traffic safety are respected in the project. Therefore, the involvement of the local civil protection agencies is limited to attesting that the projects are following the pre-defined rules of Denmark. It is also important to mention that the degree of the involvement of civil protection agencies and other actors in urban planning projects, as well as the bureaucracy around it differ from municipality to municipality.

The Australian state of Victoria provides quite a different example of existing cooperation between urban planners and emergency management institutions. Black Saturday fires in 2009, the worst bushfire disaster in Australia of all-time, triggered some positive changes in the way the urban planning system in the country works. In a personal interview, Alan March explained that after the disaster, the Minister for Planning of the Victoria state initiated establishment of urban planning system that requires referrals between different agencies such as the fire, emergency, and police services. "All of them were directly involved in the preparations of the planning system, and in the background of it an extensive hazard mapping process occurred assessing the risk profiles across the entire state. This was used as the beginning of a more detailed town planning and design process that assessed each community." However, the implementation of the new system did not come without a challenge. Acknowledging the need for a holistic approach, there was a lack of comprehensive knowledge and education in the area. "When talking about hazards one needs to understand the whole complexity of things. For example, in the case of a bushfire one needs to understand how forest works, how forest fire works, how the interaction between fire and a settlement works, one also needs to understand buildings and human behaviour in emergency situations." In 2009, there were only a few people in the whole state who had this skills set. Therefore, Australia went one step further and introduced an education covering primary school level up to the university higher degree and aiming at increasing knowledge in hazard management. According to Alan March, one part of it was the development of a post-graduate training to enable people to become experts in the area. "We developed bushfire and design qualification intended for urban planners, architects, engineers, landscape architects, forestry and ecology educated qualified people who could undertake bushfire assessment in the higher degree quality. These people can understand the whole picture from the forest to the designed structure and are capable of independently providing full bushfire risk assessment. This is almost a new profession." Therefore, Australia is far more ahead regarding the resilient urban planning processes compared not only to Denmark but also to the other European countries.

SLA urban planners also worked on several urban resilience related projects in the municipality of Vejle. They explained that being smaller municipality than Copenhagen, Vejle has less complicated bureaucratic and administrative 
procedures which allow for more fast and efficient implementation of different projects. As it was already mentioned, Vejle is participating in the "100 Resilient Cities" network since 2013, therefore, all the activities related to urban resilience are considered to be a priority in the area. Being part of the network provides municipality with endless possibilities of increasing its urban resilience, such as involving a large network of specialists, consultants, companies from Denmark and around the world in the process of building region's resilience, for example.

Contrary to Copenhagen, Vejle works in a rather close and more extensive cooperation with the municipal emergency management agencies. In addition to overseeing projects' compliance with the existing national regulations, local civil protection agencies have been involved in finding solutions for different regional challenges and building strategies. The cooperation with civil protection agencies started back in 2008 when the municipality initiated a project on water retention in the upland. Since then, local civil protection agencies are involved in resilience building related projects throughout the project cycle. We were also informed that the fire brigade reserved one lorry specifically dedicated to climate related incidents.

On the 17th March 2016, Vejle is going to present its strategy for resilience ("Vejles resiliens strategy"). It is the first European city participating in the "100 Resilient Cities" network to launch such a strategy. To the best of our knowledge, Vejle is the only municipality in Denmark with a specific strategy on resilience. We were informed that while developing the strategy, which also includes attempts to increase region's urban resilience, municipality's representatives had close collaboration with the local civil protection agencies. However, the representative of the municipality informed us that there is no cooperation with DEMA neither in the projects aimed at increasing urban resilience, nor in the process of developing the resilience strategy.

In the personal interview with a representative from DEMA, we found out that the agency has a strong focus on fire prevention and not that much on other areas, due to the lack of resources and competences. As a state agency, they are in a middle of an extensive budget cut, which forces them to make difficult decisions and prioritize. We also learned that even though they have been involved in the national strategy work done under the Hyogo framework, they still have not been tasked with doing the same under the Sendai framework. They do not see themselves as being the right agency to be responsible for the development of a national resilience strategy or coordinating regional resilience building attempts, as they feel that the challenges we face in Denmark, are more related to the Ministry of Environment or to the Police, and would then require a cooperative effort. Thus, we can conclude that DEMA is not the civil protection agency responsible for delivering resilience in Denmark. Instead, municipalities are responsible for efforts aimed at increasing local urban resilience without having any centralised guidance from DEMA.

All the Danish interviewees informed us that there is still a lack of effort to include local communities in resilience building processes in the country. We had to chance to make a comparison with Australia, where governance is based on a rather open system of fundamentals that allows for a lot of community inputs in 
different policies. This is not something that was specifically mentioned in our interviews in Denmark. However, according to Alan March, in the disaster risk reduction area, the opportunities for such inputs are rather limited. "Unstructured public participation where citizens are in control of everything does not bring a positive outcome, especially in disaster risk reduction (DRR) area. There should be well informed government and DRR specialists taking control over the whole process. Strong and clear evidence based risk assessment is the way to go. However, another and more efficient way to achieve higher urban resilience is well informed, committed community that is all about participation. For example, in Victoria there are very strong fire authorities in each of the communities and they are almost exclusively volunteers based. They are well informed, trained and equipped. They are assisted by professionals but they are very well integrated." In Denmark, we could observe that community engagement is still at a very early stage, though much more present in Vejle city than elsewhere in the country. This can be explained by the strong commitment that Vejle has to resilience and to the "100 Resilient Cities" network.

\section{Conclusion}

After performing a set of interviews with the representatives from the Danish civil protection, municipalities and urban planning agencies, it can be concluded that although all the interviewees agreed that there is an urge for a holistic and coordinated approach towards the process of building urban resilience, civil protection and urban planning systems function on different dimensions in Denmark. DEMA, as a central civil protection agency, does not plan to integrate urban planning activities into the overall civil protection system of the country. The main obstacle for the existence of such cooperation between DEMA and urban planners is the lack of resources and knowledge on DEMA side to establish itself as an organisation responsible for delivering resilience in Denmark. The concept and practice of urban resilience, as well as resilience in a general context, is in a rather early stage of development on the national level. There is no national level strategy or any kind of document related to resilience in Denmark. To the best of our knowledge, there is no intention to create one in the nearest future due to the lack of knowledge in the field of resilience.

Any efforts aimed at building urban resilience are concentrated at the municipal level. Two selected cases revealed rather different results: while in the municipality of Copenhagen, the cooperation between civil protection agencies and urban planners is rather limited, this is not the case in Vejle. In the city of Vejle, the dialogue between urban planners, municipality and civil protection representatives is quite extensive and fruitful. Although it should be stressed, that Vejle is a special case in Denmark when it comes to resilience, due to the fact that the municipality is involved in the " 100 Resilient Cities" initiative funded by Rockefeller Foundation. 


\section{References}

[1] "Managing Disaster Risks for Resilient Development," The World Bank, 2014. [Online]. Available: http://www.worldbank.org/en/results/2013/04 /12/managing-disaster-risks-resilient-development. [Accessed: 05-Feb2016].

[2] B. Cohen, "Global Ranking of Top 10 Resilient Cities," Triple Pundit, 2011. [Online]. Available: http://www.triplepundit.com/2011/06/top-10-globallyresilient-cities/. [Accessed: 05-Feb-2016].

[3] J. Gerdes, "What Copenhagen Can Teach Cities about Adapting to Climate Change," Forbes, 2011. [Online]. Available: http://www.forbes.com/ sites/justingerdes/2012/10/31/what-copenhagen-can-teach-cities-aboutadapting-to-climate-change/\#11292c986834. [Accessed: 05-Feb-2016].

[4] "Floods still affecting traffic this morning," The Copenhagen Post, 2014. [Online]. Available: http://cphpost.dk/news14/local/floods-still-affectingtraffic-this-morning.html. [Accessed: 05-Feb-2016].

[5] "Vejle's Resilience Challenge | 100 Resilient Cities," Rockefeller Foundation, 2016. [Online]. Available: http://www.100resilientcities.org/ cities/entry/vejles-resilience-challenge\#/-_. [Accessed: 05-Feb-2016].

[6] J. Gerring, Case Study Research: Principles and Practices. Cambridge University Press, 2007.

[7] A. Bryman, Social Research Methods. Oxford University Press, 2015.

[8] D. E. Alexander, "Resilience and disaster risk reduction: An etymological journey," Nat. Hazards Earth Syst. Sci., 2013.

[9] C. Folke, "Resilience: The emergence of a perspective for social-ecological systems analyses," Glob. Environ. Chang., vol. 16, no. 3, pp. 253-267, 2006.

[10] A. B. Wildavsky, Searching for Safety. Transaction Publishers, 1988.

[11] B. S. Manyena, "Disaster Resilience in Development and Humanitarian Interventions," University of Northumbria, 2009.

[12] C. S. Holling, "Resilience and Stability of Ecological Systems," Annu. Rev. Ecol. Syst., vol. 4, pp. 1-23, 1973.

[13] L. H. Gunderson, "Ecological Resilience - in Theory and Application," Annu. Rev. Ecol. Syst., vol. 31, pp. 425-439, 2000.

[14] J. Giroux and T. Prior, "Expressions of Resilience: From 'Bounce Back' to Adaptation," Zurich, Swizterland, 2012.

[15] S. B. Manyena, G. O’Brien, P. O'Keefe, and J. Rose, "Disaster resilience: a bounce back or bounce forward ability?," Local Environ., vol. 16, no. 5, pp. 417-424, 2011.

[16] United Nations, "International Strategy for Disaster Reduction Hyogo Framework for Action 2005-2015: Building the Resilience of Nations," 2005.

[17] UNISDR, "UNISDR Terminology on Disaster Risk Reduction," 2009.

[18] R. Crane and R. Weber, The Oxford Handbook of Urban Planning. New York: Oxford University Press, 2012. 
[19] M. Alberti, J. M. Marzluff, E. Shulenberger, G. Bradley, C. Ryan, and C. Zumbrunnen, "Integrating humans into ecology: Opportunities and challenges for studying urban ecosystems," Bioscience, vol. 53, no. 12, pp. 143-158, 2003.

[20] S. Meerow, J. P. Newell, and M. Stults, "Defining urban resilience: A review," Landsc. Urban Plan., vol. 147, pp. 38-49, 2016.

[21] W. A. H. Hamilton, "Resilience and the city: the water sector," Proc. ICE Urban Des. Plan., vol. 162, no. 3, pp. 109-121, Jan. 2009.

[22] D. R. Godschalk, "Urban Hazard Mitigation: Creating Resilient Cities," Nat. Hazards Rev., vol. 4, no. 3, pp. 136-143, 2003.

[23] G. Bristow, "Resilient regions: Re-'place'ing regional competitiveness," Cambridge J. Reg. Econ. Soc., vol. 3, no. 1, pp. 153-167, 2010.

[24] J. Korhonen, "Some suggestions for regional industrial ecosystemsextended industrial ecology," Eco-Management Audit. Eco-Management, vol. 69, pp. 57-69, 2001.

[25] ACCCRN, "Responding to the Urban Climate Challenge," Boulder, Colorado, USA, 2009.

[26] UN World Conference on Disaster Risk Reduction, "Reducing Disaster Risk in Urban Settings," Sendai, Japan, 2015.

[27] UNISDR, "Local Governments and Disaster Risk Reduction: Good practices and lessons learned," Geneva, Switzerland, 2010.

[28] K. Groven, C. Aall, M. van den Berg, A. Carlsson-Kanyama, and F. Coenen, "Integrating climate change adaptation into civil protection: comparative lessons from Norway, Sweden and the Netherlands," Local Environ., vol. 17, no. 6-7, pp. 679-694, 2012. 